Огляди літератури, оригінальні дослідження, погляд на проблему, ювілеї

УДК 616.12-008,616.13-004.6 + 616.24-002.153]-08.039.11

DOI 10.11603/1811-2471.2019.v0.i1.10054

\title{
ОСОБЛИВОСТІ КЛІНІЧНОГО ПЕРЕБІГУ СТАБІЛЬНОЇ ІШЕМІЧНОЇ ХВОРОБИ СЕРЦЯ В ПОЄДНАННІ ІЗ НЕГОСПІТАЛЬНОЮ ПНЕВМОНІЄЮ У ХВОРИХ ПОХИЛОГО ВІКУ - В ФОКУСІ СТАТИНИ
}

\author{
ДЗ «Запорізька медична академія післядипломної освіти МОз України» \\ Запорізький державний медичний університет
}

РЕЗЮМЕ. Стабільна ішемічна хвороба серця залишається надзвичайно актуальною медико-соціальною проблемою, що обумовлено високим рівнем захворюваності та смертності.

Мета - визначити особливості клінічного перебігу, функціональної та структурно-геометричної перебудови лівих відділів серця у хворих на стабільну IXC (CIXC) в поєднанні із нетяжкою негоспітальною пневмонією (HП) та ефективність комплексного лікування з додатковим включенням до традиційного протокольного лікування препарату Розувастатин, в добовій дозі 40 мг на ніч, на термін перебування в стаціонарі, та надалі - амбулаторно протягом 6 місяців.

Матеріал і методи. У дослідження було включено 77 пацієнтів, старших 65 років. Хворі були поділені на 3 групи: в 1 увійшли хворі на СІХС із супутньою НП (n=32), у 2 - хворі з ізольованою НП (n=27), в 3 - 18 хворих із ізольованою СІХC, які перебували на лікуванні в терапевтичному відділенні КЗ «ЦЛ Комунарського району» М. Запоріжжя, впродовж 2017 року. Середній вік хворих складав $(66,2 \pm 7,1)$ років. Чоловіків було 42, жінок - 35. Усім пацієнтам проведено загальноклінічне обстеження згідно з вітчизняними рекомендаціями. Додатково хворим була проведена ехокардіографія в М- та В-режимах. Діагноз СІХС встановлювали на підставі наказу МОЗ України № 152 від 02.03.2016 р., діагноз НП - згідно з наказом МОЗ України (№ 128 від 19.03.2007р.). Хворі на СІХС, як із поєднаним перебігом (CIXC+HП), так і з ізольованою СІХC, отримували лікування згідно з «Протоколом надання медичної допомоги хворим з ішемічною хворобою серця: стабільною стенокардією напруження» (наказ МОЗ України № 152 від 02.03.2016р.), хворі на НП - згідно з «Протоколом надання медичної допомоги хворим на НП дорослим особам» (наказ України № 128 від 19.03.2007р.).

До госпіталізації всі хворі з СІХС отримували, згідно з протоколом, статини (розувастатин) в дозі 10-20 мг. Беручи до уваги плейотропну протизапальну дію статинів і їхню здатність поліпшувати функції зовнішнього дихання за рахунок зростання показників ОФВ, ФЖЄЛ, хворим 1 і 2 груп на фоні призначення традиційної терапії НП та СІХC ми призначали розувастатин у добовій дозі 40 мг 1 раз на добу на ніч. Пацієнтам 3 групи дозу статинів, яку хворі приймали раніше, не змінювали.

Результати. За об'єктивними, лабораторними та інструментальними даними встановлено, що НП сприяє погіршенню клінічного перебігу СІХС: вірогідно вищими на 23,4 \% (p<0,05) були частота серцевих скорочень (ЧСС), на 10,1\%-частота дихальних рухів (ЧДР) (р<0,05); виявлено зниження сатурації кисню на 2,7\% (p<0,05), підвищення показників ШОЕ на 13,7 \%, лейкоцитозу - на 26,0 \% і показників імунозапальної активації - СРП - на 9,6 \% (р<0,05), порівняно із пацієнтами 3 групи (СІХС без НП). Функція зовнішнього дихання (ФЗД) у пацієнтів 1 групи була незначно порушена, в основному за рестриктивним типом. Хворі 1 групи, яким додатково призначали розувастатин у добовій дозі 40 мг, вже через 10-12 днів відмічали позитивну динаміку: поліпшення загального стану та показників крові. Скоротився також термін перебування цих хворих у стаціонарі - до $(14,2 \pm 1,1)$ днів проти $(16,62 \pm 1,0)$ $(p<0,05)$ у хворих з ізольованою СІХС, що одержували тільки традиційне лікування. Вплив призначеного комплексного лікування на прогноз СІХС після перенесеної НП вивчався сімейним лікарем амбулаторно впродовж 6 місяців потому.

Висновки. Аналіз результатів дослідження: загальний стан хворих обох груп, показники лабораторних та інструментальних досліджень, вказують на негативний вплив НП на перебіг СІХС у хворих похилого віку, на відміну від хворих з ізольованою СІХС. Комплексне ж протокольне лікування хворих з коморбідним перебігом СІХС із супутньою НП з додатковим призначенням препарату Розувастатин (40 мг на добу на ніч) у період стаціонарного лікування, - сприяє швидшому одужанню хворих від НП. Продовження ж прийому розувастатину хворими на CIXC після перенесеної НП ще протягом півроку, в тій же самій дозі, вказує на його позитивний вплив на стан кардіогемодинаміки та обумовлює більш сприятливий перебіг захворювання і покращення якості життя хворих, про що свідчить відсутність повторних госпіталізацій серед 32 хворих на СІХС, що перенесли НП, впродовж всього терміну спостереження.

КЛючОВІ слОВА: стабільна ішемічна хвороба серця; негоспітальна пневмонія; ремоделювання серця; розувастатин.

Вступ. Незважаючи на сучасні досягнення кардіології, стабільна ішемічна хвороба серця (CIXC) займає провідне місце серед серцево-судинних захворювань (ССЗ) у більшості розвинутих країн світу, в тому числі й в Україні, $є$ основною причиною втрати працездатності та смертності, а поширення цієї патології останніми роками невпинно зростає $[1,6-8]$. На сьогодні відомо, що на перебіг 
Огляди літератури, оригінальні дослідження, погляд на проблему, ювілеї

CIXC впливають супутні захворювання органів дихання, частіше негоспітальна пневмонія (НП), яка належить до групи найпоширеніших інфекційних захворювань легень [4, 5]. Не менш важливою залишається проблема діагностики та лікування коморбідного перебігу СІХС і НП у літніх людей. При цій коморбідній патології НП суттєво ускладнює перебіг CIXC, на тлі якої вона виникла. Вважають, що наявність пневмонії негативно впливає на стан хворих із СІХC за рахунок збільшення потреби міокарда у кисні в умовах інтоксикації, зниженої оксигенації та вентиляційно-перфузійних порушень. За наявності гострого запального процесу в легенях погіршуються зміни гемодинаміки, які викликають порушення функції ендотелію судин, обумовлюють тяжкість перебігу CIXC та несуть загрозу розвитку небезпечних ускладнень з боку саме серцево-судинної системи $[3,5,7]$. Останніми роками в дослідженнях, присвячених даній проблемі, та для оцінки прогнозу хворих з вказаною коморбідною патологією, вивчають структурно-геометричну та функціональну перебудову серця $[1,2,4]$. Грамотна інтерпретація особливостей ехокардіографічних показників пацієнтів 3 CIXC, поєднаної із НП, дозволяє не тільки оцінити тяжкість перебігу захворювання, а й спрогнозувати ризик ускладнень з боку серцево-судинної системи та оптимізувати лікування, як на етапі перебування хворого в стаціонарі, так і на етапі амбулаторного спостереження після перенесеної НП $[1,5,9,10]$. Питання щодо віддаленого прогнозу пацієнтів зі СІXC, які перенесли НП, залишаються актуальними, оскільки вимагають від сімейного лікаря (після виписки пацієнта із стаціонару) цілісного підходу до розуміння ведення таких хворих при амбулаторному спостереженні, своєчасного проведення необхідних обстежень, адекватної терапії, що покликана сприяти не тільки поліпшенню стану, а й покращенню та подовженню життя хворих похилого віку.

Мета - визначити особливості клінічного перебігу, функціональної та структурно-геометричної перебудови серця у хворих на IXC в поєднанні із нетяжкою НП, оптимізувати протокольне комплексне лікування з додатковим включенням розувастатину в добовій дозі 40 мг на ніч на термін перебування в стаціонарі та надалі- амбулаторно протягом 6 місяців.

Матеріал і методи дослідження. Відповідно до мети дослідження було обстежено 77 пацієнтів, старших за 65 років, з них 32 - з НП в поєднанні із СІХC, 27 - із ізольованою нетяжкою НП та 18 з ізольованою CIXC, які перебували на лікуванні в терапевтичному відділенні КУ «ЦЛ Комунарського р-ну» М. Запоріжжя, протягом 2017 року. Середній вік хворих складав $(66,13 \pm 7,1)$ років. Чоло- віків було 42, жінок - 35. Всім пацієнтам проведено загальноклінічне лабораторне та інструментальне обстеження згідно з вітчизняними рекомендаціями. Діагноз НП у всіх хворих верифіковано рентгенологічно згідно з наказом МОЗ України (№ 128 від 19.03.2007 р.). Діагноз СІХС встановлювали на підставі наказу МО3 України № 152 від 02.03.2016 р.). 3 метою оцінки структурно-функціонального стану лівих відділів серця усім пацієнтам була виконана ехокардіографія в М- та В-режимах з визначенням наступних показників: кінцевий систолічний розмір лівого шлуночка (КСР, мМ), кінцевий діастолічний розмір лівого шлуночка (КДР, Мм), кінцевий систолічний об'єм лівого шлуночка (КСО, мл), кінцевий діастолічний об'єм лівого шлуночка (КДО, мл), фракція викиду (ФВ, \%), швидкість раннього діастолічного наповнення ЛШ (E, cM/c), швидкість пізнього діастолічного наповнення ЛШ (A, cM/c), співвідношення E/A, час сповільнення хвилі (DT в MC), товщину задньої стінки ЛШ в діастолу (ТЗСЛШд, мМ), товщину міжшлуночкової перетинки в діастолу (ТМШПд, мм), масу міокарда ЛШ (ММЛШ, г), ін-

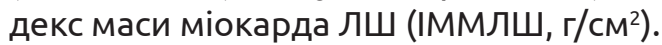

Оцінку систолічної функції ЛШ визначали враховуючи збільшення КДО, КСО та зменшення ФВ. ФВ ЛШ >50 \% вважали нормою; ФВ ЛШ 40$50 \%$ - проміжною («сірою зоною»), а <40 \% - зниженою (згідно з Рекомендаціями діагностики і лікування серцевої недостатності (2016) Европейського кардіологічного товариства [1]. Статистичну обробку виконували за допомогою пакета програм «Statistica 7.0». Застосовували параметричні та непараметричні методи. Усі статистичні тести були двобічними, значущим вважали рівень $p<0,05$.

Усім хворим на НП призначали стартову антибактеріальну терапію (АБТ) згідно з протоколом надання допомоги хворим на НП, з урахуванням попереднього використання антибіотиків. Призначали також муколітичну та дезінтоксикаційну терапію. Додатково пацієнти 1 та 2 груп з поєднаним перебігом CIXC та НП (n=32) і пацієнти з ізольованою НП (n=27), отримували препарат розувастатин в дозі 40 мг 1 раз на добу на ніч, беручи до уваги плейотропну протизапальну дію статинів та їхню здатність поліпшувати функцію зовнішнього дихання за рахунок зростання показників ОФВ, ФЖЄЛ. Ефективність лікування НП оцінювали через $(10 \pm 1,3)$ днів. Вплив призначеного комплексного лікування на прогноз CIXC, показники гемодинаміки та ЯЖ хворих із CIXC, що перенесли НП, оцінювали через 6 місяців.

Результати й обговорення. На початку госпіталізації хворі 1 і 2 груп за розподілом скарг не розрізнялися. У пацієнтів 1 основної групи такі 
Огляди літератури, оригінальні дослідження, погляд на проблему, ювілеї

скарги як задишка $(76,8 \%)$, пастозність гомілок (21,4 \%), більш виражена слабкість (54,3 \%) траплялися частіше, ніж у пацієнтів з ізольованою СІХС (відповідно16,9 \%, 0 \%, 23,4 \%, у всіх випадках $p<0,05)$. Також було виявлено різницю між 1 та 3 (хворі на СІХC без НП) групами за показниками частоти серцевих скорочень (ЧСС), відповідно $(86,9 \pm 3,0)$ та $(76,3 \pm 6,4)$ ударів за 1 хв. Частота дихальних рухів (ЧДР) у хворих основної групи складала $(20,5 \pm 0,4)$ за 1 хвилину проти $(17,6 \pm 0,2)$ за 1 хвилину у хворих на ізольовану СІХС. Особливості структурно-геометричних та функціональних показників серця у хворих на CIXC, поєднану із НП, характеризувалися достовірно збільшеними лінійними розмірами лівого передсердя у діастолу на $12,8 \%(p<0,05)$, а у систолу - на $25,1 \%$ $(p<0,05)$, порівняно із хворими на СІХС без НП. ФВ була достовірно нижчою у хворих з поєднанням СІХC і НП на 8,4 \% $(p<0,05)$. У цій групі хворих також спостерігалось збільшення товщини міжшлуночкової перетинки (ТМШП) у систолу на $11,6 \%$ та діастолу - на $12,1 \%$, а також вірогідне збільшення індексу маси міокарда (IMM) ЛШ на 24,0\% $(p<0,05)$, на відміну від пацієнтів з СІХС без супутньої НП $(p<0,05)$.

Показники функції зовнішнього дихання (ФЗД) у хворих на СІXС, поєднану із НП, і СІXС без НП, були порушені за змішаним типом, але у хворих з поєднаним перебігом більш вираженими були порушення рестриктивного типу.

При аналізі ліпідограми у хворих на СІXC із супутньою НП було відмічено достовірне підвищення вмісту загального холестерину (3Х) крові на $40,0 \%(p<0,05)$ більше, ніж у хворих з ізольованою
НП, тригліцеридів - на 19,2 \% ( $<<0,05)$, ліпопротеїдів низької щільності (ЛПНЩ) - на 69,3 \% ( $<<0,05)$, та дуже низької - на $21,1 \%(p<0,05)$ відповідно.

Проаналізовані показники ФЗД у хворих 1 i 2 груп під впливом комплексного лікування з додатковим призначенням препарату розувастатину в дозі 40 мг на добу вказали на вірогідне збільшення відсотка життєвої ємності легень (ЖЄЛ) вдиху на 10,9\% (p<0,05), форсованої життєвої ємності легень (ФЖЕЛ) вдиху - на 15,0 \% ( $<<0,05)$. Вміст 3Х у хворих на НП без супутньої СІХС під впливом комплексного лікування з додатковим призначенням розувастатину зменшився на $6,2 \%$, а лПнЩ - на $11,0 \%(p<0,05)$.

Висновки. 1. Виникнення НП на тлі СІХС сприяє більш тяжкому клінічному перебігу захворювання у осіб похилого віку.

2. У хворих на НП із супутньою СІХC має місце порушення ФЗД за змішаним типом, але з перевагою рестриктивного типу.

3. Для хворих з поєднаним перебігом НП з супутньою СІХC характерні зміни геометрії лівих відділів серця, а саме, збільшення лінійних розмірів лівих камер серця, як у діастолу, так і в систолу, КСР та КДР ЛШ у порівнянні хворими з ізольованою НП.

4. Використання в комплексному протокольному лікуванні хворих з коморбідним перебігом НП і СІХC препарату розувастатину в період лікування в стаціонарі в дозі 40 мг, сприяє покращенню загального стану та поліпшенню ФЗД, і показників центральної гемодинаміки, як у хворих із CIXC після перенесеної НП, так і у пацієнтів з перенесеною ізольованою НП.

\section{ЛІТЕРАТУРА}

1. Діденко Д. В. Особливості ремоделювання лівих та правих відділів серця пацієнтів із поєднаним перебігом ішемічної хвороби серця та хронічного обструктивного захворювання легень / Д. В. Діденко // Здобутки клінічної і експериментальної медицини. - 2017. № 3 (31). - С. 57-64.

2. Крахмалова Е. О. Эхокардиография в оценке нарушений гемодинамики у больных с негоспитальной пневмонией / Е. О. Крахмалова // Вісник морфології. 2011. - № 3 (17). - С. 555-558.

3. Кузнецова Л. Ф. Рациональная стратегия ведения пациентов с внебольничной пневмонией в пожилом и старческом воздасте / Л. Ф. Кузнецова, Т. В. Богослав, Ю. И. Решетилов // Запорожский медицинский журнал. - 2014. - № 2 (83). - С. 36-38.

4. Курілець Л. О. Особливості центральної гемодинаміки та функцій зовнішнього дихання у хворих на негоспітальну пневмонію 3 і 4 групи із супутньою IXC / Л. О. Курінець // Запорізький медичний журнал. - 2010. T. 12, № 3. - C. 21-23.
5. Лебединская М. Н. Внебольничная пневмония у больных с хронической сердечной недостаточностью: трудности диагностики: научный обзор / М. Н. Лебединская, В. И. Березняков // Болезни и антибиотики. 2012. - № 1. - С. 5-28.

6. Негоспітальна пневмонія: стандарти діагностики, сучасна антибактеріальна терапія / Т. О. Перцева, Р. С. Козлов, С. С. Симонов, В. В. Дмитриченко // Український медичний часопис. - 2011. - № 6 (86).

7. Чучалин А. Г. Пневмония: актуальная проблема XXI века / А. Г. Чучалин // Пульмонология. - 2015. - № 2. C. 133-142.

8. Epidemiology of coronary heart disease and acute coronary syndrome / F. Sanchis-Gomar, C. Perez-Quilis, R. Leischik [et al.] // Ann. Med. - 2016. - Vol. 4913. - P. 256-260.

9. Cardiac complications in patients with communityacquired pneumonia. Incidents, timing, risk factors, and association with short-term mortality / V. F. Corrales-Medina, D. M. Musher, G. A. Wells [et al.] // Circulation. - 2012. Vol. 125. - P. 773-781. 
Огляди літератури, оригінальні дослідження, погляд на проблему, ювілеї

10. Cardiovascular disease in Europe Epidemiological update 2016 / N. Townsend, L. Wilson, P. Bhatnager [et. al.]

// Eur. Heart J. - 2016. - Mode access : htth:// dx.doi.org/ 10. 1093/eurheartj/ ehw334.

\title{
REFERENCES
}

1. Didenko, D.V. (2017). Osoblyvosti remodeliuvannia livykh ta pravykh viddiliv sertsia patsiientiv iz poiednanym perebihom ishemichnoi khvoroby sertsia ta khronichnoho obstruktyvnoho zakhvoriuvannia lehen [Features of remodeling of the left and right heart departments of patients with a combined course of coronary heart disease and chronic obstructive pulmonary disease]. Zdobutky klinichnoi i eksperymentalnoi medytsyny-Achievements of Clinical and Experimental Medicine, 3 (31), 57-64 [in Ukrainian].

2. Krakhmalova, E.O. (2011). Ekhokardiofrafiya v otsenke narusheniy gemodinamiky u bolnykh $\mathrm{s}$ negospitalnoy pnevmoniey [Echocardiography in the assessment of hemodynamic disorders in patients with non-hospital pneumonia]. Visnyk morfolohii - Bulletin of Morphology, 3 (17), 555-558 [in Russian].

3. Kuznetsova, L.F., Bohoslav, T.V., \& Reshetylov, Yu.I. (2014). Ratsyonalnaya strategiya vedeniya patsiyentov $s$ vnebolnichnoy pnevmoniyey $\mathrm{v}$ pozhylom i starcheskom vozraste [Rational management strategy for patients with community-acquired pneumonia in the elderly and senile patients]. Zaporozhskiy meditsynskiy zhurnal -Zaporizhzhia Medical Journal, 2 (83), 36-38 [in Russian].

4. Kurilets, L.O. (2010). Osoblyvosti tsentralnoi hemodinamiky ta funktsii zovnishnoho dykhannia u khvorykh na nehospitalnu pnevmoniiu 3 i 4 hrupy iz suputnioiu IKhS [Features of central hemodynamics and external respiration functions in patients with community-acquired pneumonia of groups 3 and 4 with concomitant coronary artery disease]. Zaporizkyi medychnyi zhurnal - Zaporizhzhia Medical Journal, 12 (3), 21-23 [in Ukrainian].

5. Lebedinskaya, M.N., \& Bereznyakov, V.I. (2012). Vnebolnichnaya pnevmoniya u bolnykh s khronicheskoy serdechnoy nedostatochnostyu: trudnosti diagnostiky: nauchnyy obzor [Community-acquired pneumonia in patients with chronic heart failure: diagnostic difficulties: a scientific review]. Bolezni $i$ antibiotiky - Diseases and Antibiotics, 1, 5-28 [in Russian].

6. Pertseva, T.O., Kozlov, R.S., Symonov, S.S., \& Dmytrychenko, V.V. (2011). Nehospitalna pnevmoniia: standarty diahnostyky, suchasna antybakterialna terapiia [Untreated pneumonia: diagnostic standards, modern antibiotic therapy]. Ukrainskyi medychnyi chasopys - Ukrainian Medical Bulletin, 6 (86) [in Ukrainian].

7. Chuchalyn, A.H. (2015). Pnevmoniya: aktualnaya problema XXI veka [Pneumonia: an actual problem of the XXI century]. Pulmonologiya - Pulmonology, 2, 133-142 [in Russian].

8. Sanchis-Gomar, F., Perez-Quilis, C., \& Leischik, R. (2016). Epidemiology of coronary heart disease and acute coronary syndrome. Ann. Med., 49 (13), 256-260.

9. Corrales-Medina, V.F., Musher, D.M., \& Wells, G.A. (2012). Cardiac complications in patients with communityacquired pneumonia. Incidents, timing, risk factors, and association with short-term mortality. Circulation, 125, 773-781.

10. Townsend, N., Wilson, L., \& Bhatnager, P. (2016). Cardiovascular disease in Europe Epidemiological update 2016. Eur. Heart J. Retrieved from: htth:// dx.doi.org/ 10. 1093/eurheartj/ ehw334.

\section{ОСОБЕННОСТИ КЛИНИЧЕСКОГО ТЕЧЕНИЯ СТАБИЛЬНОЙ ИШЕМИЧЕСКОЙ БОЛЕЗНИ СЕРДЦА В СОЧЕТАНИИ С НЕГОСПИТАЛЬНОЙ ПНЕВМОНИЕЙ У БОЛЬНЫХ ПОЖИЛОГО ВОЗРАСТА - В ФОКУСЕ СТАТИНЫ}

\author{
๑Л. Ф. Кузнецова, Т. В. Богослав

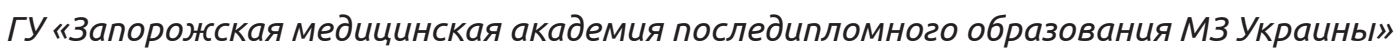 \\ Запорожский государственный медицинский университет
}

РЕЗЮМЕ. Стабильная ишемическая болезнь сердца остается актуальнейшей медико-социальной проблемой, что обусловлено високим уровнем заболеваемости и смертности.

Цель - определить особенности клинического течения, функциональной и структурной перестройки левых отделов сердца у больных со стабильной ишемической болезнью сердца (СИБС) в сочетании с негоспитальной пневмонией (НП) и эффективность лечения с дополнительным включением в комплексное традиционное лечение препарата Розувастатин в суточной дозе 40 мг вечером, на весь период лечения в стационаре и, в дальнейшем, амбулаторно в течение 6 месяцев.

Материал и методы. В исследование были включены 77 пациентов в возрасте старше 65 лет. Больные были поделены на 3 группы: в 1 вошли больные СИБС с сопутствующей НП ( $\mathrm{n}=32)$, во 2 - больные с изолированной НП (n=27), в 3-18 больных с изолированной СИБС, которые находились на лечении в терапевтическом отделении КУ «ЦБ Коммунарского района» г. Запорожья на протяжении 2017 года. Средний возраст больных составлял $(66,2 \pm 7,1)$ лет. Мужчин было 42, женщин - 35. Всем пациентам проведено клиническое обследование согласно отечественным рекомендациям. Дополнительно больным была проведена эхокардиография в М- и В-режимах. Диагноз СИБС устанавливали на основании приказа МЗ Украины № 152 от 02.03.2016 г., диагноз НП - согласно приказу МЗ Украины № 128 от 19.03.2007 г. Больные СИБС, как с совмещенным течением (СИБС + НП), так и с 
Огляди літератури, оригінальні дослідження, погляд на проблему, ювілеї

изолированной СИБС, получали лечение согласно «Протоколу оказания медицинской помощи больным с ишемической болезнью сердца: стабильной стенокардией напряжения» (приказ МЗ Украины №152 от 02.03.2016 г.), больные НП - согласно «Протоколу оказания медицинской помощи больным НП взрослым лицам» (приказ Украины № 128 от 19.03.2007 г.).

До госпитализации все больные с СИБС получали, согласно протоколу, статины (розувастатин) в дозе 1020 мг. Принимая во внимание плейотропное противовоспалительное действие статинов и их способность улучшать функции внешнего дыхания за счет роста показателей ОФВ, ФЖЕЛ, больным 1 группы на фоне назначения традиционной терапии НП и СИБС, мы назначали препарат розувастатин в дозе 40 мг 1 раз в сутки на ночь. Пациентам 2 группы дозу статинов, которую больные принимали ранее, не изменяли.

Результаты. По объективным, лабораторным и инструментальным данным установлено, что НП способствует ухудшению клинического течения СИБС: достоверно выше на 23,4 \% $(p<0,05)$ была частота сердечных сокращений (ЧСС), на 10,1 \% - частота дыхательных движений (ЧДД) (р<0,05); выявлено снижение сатурации кислорода на 2,7 \% (р<0,05), повышение показателей СОЭ на 13,7 \%, лейкоцитоза - на 26,0 \% и показателей иммуновоспалительной активации - СРП - на 9,6 \% ( $<<0,05)$, по сравнению с пациентами 2 группы (СИБС без НП). Функция внешнего дыхания (ФВД) у пациентов 1 группы была незначительно нарушена, в основном по рестриктивному типу. Больные 1 группы, которым дополнительно назначался розувастатин в дозе 40 мг, уже через 10-12 дней отмечали положительную динамику: улучшение общего состояния и показателей крови. Сократился также срок пребывания этих больных в стационаре до $(14,2 \pm 1,1)$ дней против $(16,62 \pm 1,0)(p<0,05)$ у больных с изолированной СИБС, получавших только традиционное лечение. Влияние назначенного комплексного лечения на прогноз СИБС после перенесенной НП изучался семейным врачом амбулаторно в течение 6 месяцев спустя.

Выводы. Анализ результатов исследования: общее состояние больных обеих групп, показатели лабораторных и инструментальных исследований, указывают на негативное влияние НП на ход СИБС у больных пожилого возраста, в отличие от больных с изолированной СИБС. Комплексное же протокольное лечение больных с коморбидной СИБС с сопутствующей НП с дополнительным назначением препарата розувастатина (40 мг в сутки на ночь) в период стационарного лечения способствует более быстрому выздоровлению больных от НП. Продолжение же приема розувастатина больными СИБС после перенесенной НП еще в течение полугода, в той же самой дозе, указывает на его положительное влияние на состояние кардиогемодинамики и обусловливает более благоприятное течение заболевания и улучшение качества жизни больных, о чем свидетельствует отсутствие повторных госпитализаций среди 32 больных СИБС, перенесших НП, на протяжении всего срока наблюдения.

КЛЮчЕВЫЕ СЛОВА: стабильная ишемическая болезнь сердца; внебольничная пневмония; ремоделирование сердца; розувастатин.

\title{
FEATURES OF THE CLINICAL COURSE OF STABLE ISCHEMIC HEART DISEASE IN COMBINATION WITH COMMUNITY-ACQUIRED PNEUMONIA IN ELDERLY PATIENTS, IN THE FOCUS OF STATINS
}

\author{
@L. P. Kuznetsova, T. V. Bogoslav \\ Zaporizhzhia Medical Academy of Postgraduate Education \\ Zaporizhia State Medical University
}

SUMMARY. Despite modern advances in cardiology, stable ischemic heart disease remains the most urgent medical and social problem, which is caused by a high level of morbidity and mortality.

The aim of the study - to determine the clinical course, functional and structural restructuring of the left heart departments in patients with stable ischemic heart disease in combination with community-acquired pneumonia and the effectiveness of treatment with additional inclusion in the complex traditional treatment of rosuvastatin in a daily dose of $40 \mathrm{mg}$ in the evening, for the entire period of treatment in the hospital and, further, on an outpatient basis for 6 months.

Material and Methods. The study included 77 patients over the age of 65 years. The patients were divided into 3 groups: the group 1 included patients with stable ischemic heart disease with concomitant community-acquired pneumonia ( $n=32)$, the group 2 - patients with isolated community-acquired pneumonia ( $n=27)$, the group $3-18$ patients with isolated stable ischemic heart disease who were treated in the therapeutic Department of the Hospital of Communard district, Zaporizhzhia during 2017. The average age of patients was (66.2 \pm 7.1 ) years. There were 42 men and 35 women. All patients had a general-clinical examination according to domestic recommendations. Additionally, patients had echocardiography in M- and B-modes. Diagnosis of stable ischemic heart disease was established on the basis of the order of the Ministry of Health of Ukraine No. 152 dated 02.03.2016. Diagnosis of emergency situations according to the order of the Ministry of Health of Ukraine (No. 128 dated March 19, 2007). Patients with stable ischemic heart disease as a combined course (stable ischemic heart disease + community-acquired pneumonia) and with isolated stable ischemic heart disease received treatment in accordance with the "Protocol providing medical care to patients with ischemic heart disease: stable angina tension" (Order of the Ministry of Health of Ukraine No. 152 dated 02.03.2016), patients on the state of emergency - according to the "Protocol on the provision of medical care to patients with infectious diseases of adult persons" (Order of Ukraine No. 128 dated March 19, 2007). 


\section{Огляди літератури, оригінальні дослідження, погляд на проблему, ювілеї}

Prior to hospitalization, all patients with stable ischemic heart disease received, according to the protocol, statins (rosuvastatin) in a dose of 10-20 mg. Taking into account the pleiotropic anti-inflammatory action of statins and their ability to improve the function of external respiration, due to the growth of FEV, forced lung capacity, patients in group 1 , against the appointment of traditional therapy community-acquired pneumonia and stable ischemic heart disease, we prescribed rosuvastatin daily dose $40 \mathrm{mg} 1$ time day by night. Patients in group 2, the dose of statins that patients had taken earlier, did not change.

Results. According to objective, laboratory and instrumental data, it was established that the community-acquired pneumonia contributes to the worsening of the clinical course of stable ischemic heart disease: the heart rate and the frequency of respiratory movements were significantly higher by $23.4 \%(p<0.05)-$ by $10.1 \%(p<0.05)$, reduction of oxygen saturation by $2.7 \%(p<0.05)$, increase in ESR indices by $13.7 \%$, leukocytosis - by $26.0 \%$, and indicators of immune activating activation - CRP - on $9.6 \%(p<0.05)$ in comparison with patients of the group 2 (stable ischemic heart disease without community-acquired pneumonia). The function of external respiration in patients of the group 1 was slightly violated basically - by the restrictive type. Patients in group 1 who were additionally assigned rosuvastatin in a daily dose of $40 \mathrm{mg}$, after $10-12$ days, positive dynamics was observed: improvement of the general condition and blood parameters. Also, the period of stay of these patients in the hospital was $(14.2 \pm 1.1)$ days versus $(16.62 \pm 1.0)(p<0.05)$ in patients with isolated stable ischemic heart disease who received only traditional treatment. The effect of the intended comprehensive treatment on the prognosis of stable ischemic heart disease, after a postponed community-acquired pneumonia, was studied by a family doctor outpatient for 6 months later.

Conclusions. Analysis of the results of the study: the general condition of patients in both groups, the indicators of laboratory and instrumental studies, indicate the negative impact of community-acquired pneumonia on the flow of stable ischemic heart diseases in patients of the elderly, in contrast to patients with isolated stable ischemic heart disease. Comprehensive protocol treatment for patients with comorbid flow of SIC stable ischemic heart diseases with concomitant community-acquired pneumonia with an additional appointment of the drug rosuvastatin (40 $\mathrm{mg}$ per night per night) during inpatient treatment - promotes faster recovery of patients with community-acquired pneumonia. Continuation of the same taking rosuvastatin patients with stable ischemic heart disease after the transferred community-acquired pneumonia for another six months, at the same dose, indicates its positive effect on the state of cardioghemodynamics, and causes a more favorable course of the disease and improve the quality of life of patients, as evidenced by the absence of repeated hospitalizations among 32 patients with stable ischemic heart disease who have undergone community-acquired pneumonia, during the entire period of observation.

KEY WORDS: stable ischemic heart disease; community-acquired pneumonia; heart remodeling; rosuvastatin.

Отримано 12.01.2019 